\title{
AS DIFICULDADES DE ERRADICAÇÃO DO TRABALHO ESCRAVO NO BRASIL HOJE E A EXPOSIÇÃO DOS MUITOS DESAFIOS POSTOS AO DESENVOLVIMENTO HUMANO
}

\author{
Maria José de Rezende ${ }^{1}$ \\ Rita de Cássia Rezende ${ }^{2}$ \\ Universidade Estadual de Londrina, Brasil
}

http://dx.doi.org/10.5209/rev_NOMA.2013.42349

\begin{abstract}
Resumo.- As orientações do Programa das Nações Unidas para o Desenvolvimento (PNUD) visam incentivar, os estados nacionais, a investir todos os esforços possíveis para gerar ações que levem simultaneamente tanto ao melhoramento dos índices de desenvolvimento humano quanto à efetivação dos direitos humanos, têm sido obstadas, entre inúmeras outras razões, pelas dificuldades de erradicação do trabalho escravo no Brasil. Nos Relatórios do Desenvolvimento Humano (RDHs) estão as sugestões sobre os propósitos comuns que devem embasar a vida política dos diversos países que são membros das Nações Unidas: ampliação, para os segmentos mais pobres, da renda, da longevidade, da educação e do acesso aos direitos e às liberdades. Entre estas últimas está a liberdade de possuir um trabalho decente. De um lado, estão as sugestões dos RDHs e, de outro, os procedimentos do Executivo, do Legislativo e do Judiciário que ajudam, ou não, a viabilizar os propósitos postos nos documentos das Nações Unidas.
\end{abstract}

Palavras-chaves.- desenvolvimento humano, direitos humanos, pobreza, desigualdades, trabalho escravo

The difficulties to eradicate slave labor in Brazil showing the many challenges posed to human development

\begin{abstract}
The purpose of this research is to demonstrate that the guidelines of the United Nations Development Program (UNDP) to encourage national states to invest every possible effort to generate actions that lead simultaneously to both the improvement of human development indices and the effectiveness of human rights have been challenged, among many other reasons that will not be discussed in this article, by the difficulties to eradicate the slave labor in Brazil. The research was based on the Human Development Reports (HDRs) to comply with their suggestions about the common purposes which should base the political life of the countries that are UN members: the increase, to the poorest segments, of the income and longevity, improvement of education and access to rights and liberties. Among the latter is the freedom of having a decent job. On one side are the suggestions of the HDRs, and on the other are the procedures of the executive, legislative and judicial branches that help or not to enable the purposes presented in UN documents.
\end{abstract}

Keywords.- human development, human rights, poverty, inequality, slave labor

\footnotetext{
${ }^{1}$ Doutora em Sociologia pela Universidade de São Paulo. Professora de Sociologia na Universidade Estadual de Londrina (Brasil) E-mail: mjderezende@gmail.com

2 Advogada. Especialista em Direito civil e processual civil e em Filosofia moderna e contemporânea pela Universidade Estadual de Londrina (Brasil). E-mail: ritarezende@bol.com.br
} 


\section{Introdução}

Os Relatórios do Desenvolvimento Humano (RDHs), publicados desde 1990 pelo PNUD (Programa das Nações Unidas para o Desenvolvimento), têm insistido que o desenvolvimento humano é indissociável dos direitos humanos. Isso porque tanto o primeiro quanto o segundo estão voltados para o objetivo de garantir a "liberdade, o bem-estar e a dignidade" (RDH, 2000, p.1) de todos os indivíduos, isto é, nas mais diversas partes do planeta. Em razão das dificuldades, no Brasil, de cumprir esses propósitos, demonstrar-se-á que a não-erradicação do trabalho escravo, no país, constitui-se o entrave mais evidente que se opõe ao desenvolvimento humano ${ }^{3}$.

O objetivo deste artigo é demonstrar que as dificuldades de eliminação do trabalho escravo revelam o quanto o país está distante da efetivação dos direitos humanos e, por conseguinte, do desenvolvimento humano. O problema sociológico que norteará este estudo é: De que forma a lentidão, no Brasil, em cumprir os tratados internacionais, a Carta Constitucional, as leis, os decretos, os Planos Nacionais de Defesa dos Direitos Humanos e de Erradicação do Trabalho Escravo (2003) depõe contra as possibilidades de avanços do desenvolvimento humano?

Parte-se do pressuposto de que, enquanto houver grupos sociais submetidos ao trabalho em condições análogas às de escravo, não há possibilidade de caminhar rumo à efetivação do desenvolvimento humano. Desse modo, o Brasil possui ainda um longo caminho a percorrer para que possa ser reconhecido como capaz de cumprir as metas propostas nos RDHs e nos ODMs (Objetivos do Desenvolvimento do Milênio). Não há dúvida de que, nos governos Cardoso e Lula da Silva, ocorreram investimentos de grande monta destinados a forçar procedimentos capazes de levar os poderes Executivo, Legislativo e Judiciário a institucionalizar compromissos que tornassem realidade os direitos humanos no país, mas cada passo estava amarrado por centenas de estratégias de resistência ao processo de combate ao trabalho escravo ${ }^{4}$.

Demonstrar-se-á, então, como estão presentes, nos procedimentos dos diversos poderes, das lideranças políticas, de organizações da sociedade civil, dos funcionários do Estado, entre outros, atitudes tanto impulsionadoras quanto bloqueadoras do desenvolvimento humano e dos direitos humanos.

\footnotetext{
${ }^{3}$ Desde a década de 1980, lideranças da sociedade civil e intelectuais têm demonstrado como o trabalho escravo tem estado presente no país. Entre inúmeros materiais podem ser destacados: (Martins, 1984; 1986; 1995; Lima, 1993; Almeida, 1988; 1990; Esterci, 1987; Barrozo, 1992; Sutton, 1994; Rezende Figueira, 1992; 1999; 2004; 2009). Ver ainda: (Relatório da Rede Social de Justiça e Direitos Humanos).

${ }^{4}$ Sobre o debate teórico, político e jurídico acerca da caracterização do trabalho escravo no Brasil atual, ver: (Palo, 2008; Pereira, 2008; Romero e Sprandel, 2003; Santos, 2008; Silva, 2007, Silva, 1999).
} 


\section{Desenvolvimento humano: um desafio posto às sociedades com indivíduos que vivem em situação de pobreza absoluta}

Não há dúvida de que em todas as sociedades onde há pessoas na condição de pobreza absoluta, há profundas dificuldades de avanços que tornem real o desenvolvimento humano. Sem este não há direitos humanos e sem estes não há como perseguir melhoramentos de renda, de longevidade, de educação, de bem-estar coletivo e de ampliação das liberdades ${ }^{5}$. No texto Direitos Humanos e desenvolvimento humano: em prol da liberdade e da solidariedade, o qual compõe o RDH de 2000, cuja temática é a defesa da prevalência dos direitos para todos os indivíduos e não somente para alguns, está posto que, entre as diversas outras liberdades que os estados, a sociedade civil, as lideranças políticas, entre outros, devem perseguir, está a "liberdade de ter um trabalho decente, sem exploração" (Nações Unidas, PNUD, RDH, 2000). Esta é uma condição sine qua non para que haja desenvolvimento humano. A sua viabilização, segundo os RDHs, depende de "indivíduos, governos, organizações não-governamentais (ONG), empresas, dirigentes políticos e organizações multilaterais" (Nações Unidas, PNUD, RDH, 2000, p.1).

Neste artigo não será discutido o peso que o PNUD atribui a cada um desses agentes, nem mesmo se, ao fazer isso, ele dilui, ou não, a responsabilidade do Estado em fazer cumprir os direitos fundamentais e humanos, os quais são condição para expansão das melhorias sociais dos grupos mergulhados na extrema pobreza. Mesmo tendo ciência de que os avanços dependem de ações políticas de diversos segmentos sociais, este estudo está dando centralidade ao modo como o Executivo, o Legislativo e o Judiciário impulsionam, ou não, procedimentos que podem levar ao cumprimento dos pactos internacionais e das leis internas a fim de que, na base do desenvolvimento humano, esteja posto o empenho diuturno para a erradicação de formas de trabalho análogas às de escravo que persistem tanto nas zonas rurais (Sutton, 1994; Martins, 1995; Rezende Figueira, 1992) quanto nas urbanas (Barreto, 2008).

O que distingue, como ressaltam os RDHs, as diversas nações é o modo como elas se empenham para garantir a dignidade e a liberdade humanas ${ }^{6}$. As sociedades revelam suas mais profundas características através das medidas que são tomadas em prol da abolição das injustiças e da opressão extrema (Nações Unidas, PNUD, RDH, 2000). É possível partir dessas questões para refletir sobre o modo como o país vem se voltando para o combate ao trabalho em condição análoga à de escravo ${ }^{7}$. O Brasil, como signatário de todos os

\footnotetext{
5 "Em suma, o desenvolvimento humano é essencial para fazer realidade os direitos humanos, e os direitos humanos são essenciais para o pleno desenvolvimento humano" (Nações Unidas, PNUD, RDH, 2000, p.2)

${ }^{6}$ Norbert Elias considera que a luta por melhorias coletivas é o fundamento de todo processo civilizacional que está voltado para a ampliação da capacidade, das pessoas, de identificaremse com aqueles que não fazem parte de seu grupo social e, assim, empenharem-se, diuturnamente, para abolir o sofrimento social de todos e não só de alguns. As ações em prol da ampliação para todos do desenvolvimento humano e dos direitos humanos faz parte de um processo civilizacional, nos moldes postos por Elias (1994; 2006; 2006a; 20006b). Sobre a utilização das reflexões de Elias para pensar os contextos sociais sul-americanos, ver: (Kaplan, 2008; Kaplan y Once, 2009).

Entre 1995 e 2010 foram resgatados da condição análoga à da escravidão, aproximadamente, 38 mil trabalhadores. Como há muito a ser feito para a eliminação completa
} 
pactos internacionais que visam garantir a dignidade e a liberdade das pessoas, passa, então, a estar pressionado a estabelecer políticas duradouras de combate às injustiças que têm colocado o país entre os que não conseguem situar-se no âmbito das exigências dos tratados internacionais e da própria Constituição Federal ${ }^{8}$.

Em junho de 2010, a relatora especial sobre formas contemporâneas de escravidão, Gulnara Shahinian, das Nações Unidas (ONU), esteve no Brasil para colher informações sobre o modo como o Estado brasileiro tem envidado esforços para encontrar formas eficazes de combater uma das piores mazelas sociais do mundo atual ${ }^{9}$. Pode-se dizer que esse tipo de ação da relatora é uma forma de pressionar os estados nacionais a cumprir o que foi acordado nos tratados, convenções e pactos internacionais. Isso está em consonância com as sugestões dadas pelo RDH de 2000. Se o trabalho degradante é uma prova irrefutável do desrespeito aos direitos fundamentais, isso é, sem dúvida, um obstáculo para a expansão do desenvolvimento humano, porque "os direitos humanos atraem a atenção sobre a responsabilidade para o respeito, a proteção e o cumprimento dos direitos humanos de todas as pessoas" (Nações Unidas, PNUD, RDH, 2000, p.2).

Ao lerem-se as propostas dos RDHs (Nações Unidas, PNUD, RDH 1990; 1993; 1996; 2002; 2003; 2006) aos diversos países, que são membros das Nações Unidas, saltam aos olhos o quão difícil é, no Brasil e em muitos outros países, efetivar, para todos e não somente para alguns, os direitos. Os trabalhos análogos à condição de escravos só existem porque, uma parte da sociedade brasileira, por estar mergulhada na pobreza absoluta, não possui respeitados nem sequer os direitos fundamentais. Isso coloca em xeque os avanços no IDH (Índice de Desenvolvimento Humano), já que ele não pode ser calculado com base somente nas melhorias alcançadas por uma parte do país, o qual possui, há muito tempo, uma lógica conhecida como "dar mais aos mesmos" (Draibe, 2003, p.70). Aos detentores de direitos, mais direitos. Aos excluídos perpetuase o não-respeito por qualquer de seus direitos. E isso é preocupante, porque há uma

"desigualdade e [uma] marginalização [crescente] (...) dos países pobres e das pessoas pobres. As desigualdades de renda em escala mundial aumentaram no século $X X$ em ordens de magnitude sem proporção com nada do anteriormente experimentado. (...) Um estudo recente da distribuição da renda mundial entre os lares indica um aumento abrupto da desigualdade (...). Segue sendo [a desigualdade de renda] muito elevada em grande parte da América Latina" (Nações Unidas, PNUD, RDH, 2000, p.6).

O desenvolvimento humano, conforme afirma o RDH de 2000, exige que se volte à atenção "ao contexto socioeconômico em que se pode fazer realidade

de tais condições, é possível estimar que existe, ainda, um número significativo de trabalhadores cativos no Brasil atual. Ver sobre isto:

8 O ministro do Supremo Tribunal Federal, Carlos Ayres Brito, no I Encontro Nacional pela Erradicação do Trabalho Escravo, em 2010, considerou que são muitas as "inconstitucionalidades do trabalho escravo" (Aires Brito apud Vannuci (2010).

${ }^{9}$ Assinale-se que tem sido crescente em muitas partes do mundo o reaparecimento do trabalho degradante que se traduz, sem sombra de dúvida, em novas formas de escravidão. No caso do Brasil, estas têm sido encontradas tanto na zona rural como na urbana. Ver: TRABALHO degradante cresce em obras (2011). 
os direitos, ou ameaçá-los. Os conceitos e instrumentos do desenvolvimento humano [exige] uma avaliação sistemática das limitações econômicas e institucionais para tornar realidade os direitos" (Nações Unidas, PNUD, RDH, 2000 , p.2). Assim sendo, cabem muitas ações e procedimentos para que os segmentos econômicos que utilizam trabalho em condição análoga à de escravo sejam, de fato, punidos. Os relatórios deixam claro que $A$ Carta das Nações de 1945 e a Declaração Universal dos Direitos Humanos de 1948, se cumpridas, levam a avanços expressivos no que diz respeito à grande variedade de direitos (civis, políticos, econômicos, sociais e culturais). Às vezes, os RDHs exaltam muito mais o fato de um número cada vez maior de estados subscreverem os tratados internacionais do que o fato de existirem inúmeros países que aderem a tais pactos, mas têm dificuldades enormes para colocar em funcionamento aquilo que foi pactuado. O Brasil, como será visto a seguir, está, ainda, nessa condição. Dizem os preparadores do relatório de 2000:

"Mais de 140 países tem ratificado (...) os convênios que proíbem o trabalho forçado ou a discriminação no emprego (...). Mas subsistem problemas graves. Pelo menos 150 milhões dos trabalhadores do mundo estavam desempregados no final de 1998. (...) Nos países em desenvolvimento há uns 250 milhões de crianças trabalhadoras" (Nações Unidas, PNUD, RDH, 2000, p.5).

E os RDHs perguntam: a quem cabe a responsabilidade de fazer com que os compromissos internacionais sejam cumpridos? Ao Estado. Daí a importância de analisar a atuação do Executivo, do Legislativo e do Judiciário no processo de combate ao trabalho escravo e de avaliar os avanços e não-avanços. Isso porquê, segundo dizem os formuladores dos relatórios, são necessários métodos novos e audaciosos para fazer valer os direitos e o desenvolvimento humanos. Todavia, não há como supor, conforme consta nos relatórios, que haja qualquer automaticidade na garantia das liberdades. As diversas organizações e movimentos sociais terão de lutar para "despertar a consciência pública acerca das violações de direitos e pressionar em prol de mudanças jurídicas e políticas" (Nações Unidas, PNUD, RDH, 2000, p.6).

Diz o RDH de 2000 que a possibilidade de tais mudanças é confrontada cotidianamente pelo grau de desigualdade e de marginalização das pessoas mais pobres em todo mundo. A garantia dos direitos fundamentais, para todos os habitantes, exige, afirma o RDH de 2000, "o fortalecimento de mecanismos sociais para garantir as liberdades humanas, com normas, instituições, marcos jurídicos e uma atmosfera econômica propicia" (Nações Unidas, PNUD, RDH, 2000, p.6). Alerta-se, então, que a existência da legislação é imprescindível, mas não basta, em razão do fato de que ela "por si só não pode garantir os diretos humanos. É necessário ademais instituições para apoiar o processo jurídico, assim como uma cultura de normas e ética sociais para reforçar, não ameaçar, as estruturas jurídicas" (Nações Unidas, PNUD, RDH, 2000, p.6).

O que os RDHs consideram condições econômicas propícias para impulsionar o cumprimento dos direitos humanos de todos os grupos sociais sem exceção? Segundo eles, existindo parcelas da população que vivem na pobreza extrema é "difícil constituir uma estrutura que baste para garantir todos os direitos humanos a todos os habitantes" (Nações Unidas, PNUD, RDH, 2000, p.6). 
Desse modo, fica claro que os relatórios consideram que o desenvolvimento humano está na base da ampliação dos direitos humanos.

As dificuldades de erradicação do trabalho escravo no Brasil põem às claras que a existência de grupos sociais mergulhados na pobreza extrema gera profundos entraves ao desenvolvimento humano e aos direitos humanos. Se aquele é caracterizado como melhoria na condição de renda, de longevidade e de educação e estes como a garantia das liberdades (de realizar as potencialidades humanas, de não sofrer ameaças, de ter acesso à justiça, de participar na vida social, econômica e política, de ter um trabalho decente, de não ser submetido a formas de exploração diversas, etc.), vê-se que um não tem como se realizar, de fato, sem o outro. Há RDHs, como o de 2002, que alerta para o fato de que essa indissociabilidade define o comprometimento dos proponentes dos relatórios com a democracia.

Assinale-se que um país pode alcançar melhor renda, longevidade e educação para alguns e/ou para todos, mas sem desenvolver mecanismos sociais que garantam as liberdades. Isso ocorre em situações autoritárias. Pode haver também situação em que formalmente as liberdades estariam em vigor, mas não efetivamente para uma parte da população que, por razões de pobreza e de miserabilidade, não tem qualquer de seus direitos fundamentais respeitados. Por isso, desenvolvimento humano, direitos humanos e democracia são indissociáveis, segundo os RDHs.

\section{Da evolução da legislação brasileira de combate ao trabalho escravo e em condições análogas - atuação do Executivo e do Legislativo na produção de normas e leis}

No que diz respeito ao combate ao trabalho escravo e em condições análogas, no Brasil atual, utiliza-se neste artigo a abordagem clássica da tripartição dos poderes em um estado democrático, vigorante no Brasil por força do artigo $2^{\circ}$ da Constituição Federal, que, atribuindo ao Legislativo a função de produzir as leis, ao Executivo a função de administração e aplicação de ofício das leis e ao Judiciário o julgamento dos casos a ele submetidos, tem por fundamento a legislação. Destaque-se que tal abordagem tripartite se dá apenas para facilitar a análise e a explanação, pois, sendo independentes os poderes, mas harmônicos entre si, as atividades de cada um, exercem, entre eles, influências recíprocas.

É necessário, também, apontar a historicidade dos conceitos de estado de direito, de democracia e de direitos fundamentais, razão pela qual se abordam aqui os direitos fundamentais individuais da liberdade, da igualdade, da dignidade da pessoa humana e o direito fundamental social do trabalho como direitos positivados por um ordenamento jurídico contextualizado num dado momento histórico de uma sociedade, em razão das lutas sociais pela sua conquista, situados estes direitos no terreno político da soberania popular e nela fundados (SILVA, 2004, p. 180-1).

No Brasil, após mais de três séculos de regime escravocrata, período no qual as práticas da sociedade do Império, amparadas em lei, manejaram a captura, o transporte, o comércio e a exploração de seres humanos até o exaurimento 
de suas forças físicas e psíquicas, instituiu-se em 1888, sob pressão de movimentos abolicionistas a Lei Áurea (Lei $n^{\circ} 3.353$, de 13 de maio de 1888), a qual aboliu a escravatura no Brasil.

Desde a Constituição de 1891, passando pela Constituição de 1934, estava assegurado aos brasileiros e aos estrangeiros residentes no país o direito à liberdade. Também a Constituição de 1946 e até mesmo as constituições ditatoriais de 1967 e 1969 asseguravam o direito à liberdade, destacando-se que a Constituição de 1946 já trazia em seu artigo 145 o direito à subsistência, garantindo o direito a trabalho que assegurasse existência digna, enquanto que aquelas de 1967 e 1969 abarcavam direitos fundamentais sociais (SILVA, 2004, p.170-1).

A Carta das Nações Unidas (São Francisco, Califórnia-EUA), assinada em 26 de junho de 1945, aprovada pelo Brasil pelo Decreto-lei ${ }^{10} \mathrm{n}^{0} 7.935$, de 04 de setembro de 1945 e promulgado pelo Decreto ${ }^{11} n^{0} 19.841$, de 22 de outubro de 1945, estabeleceu a organização internacional até hoje conhecida como Organização das Nações Unidas ${ }^{12}$.

Apesar de possuir constituições que asseguravam direitos fundamentais, especialmente a liberdade; apesar de fazer parte da Organização das Nações Unidas; apesar de estar apto, tanto da perspectiva interna, quanto da internacional, à aprovação e promulgação das Convenções e dos Tratados internacionais, o Brasil demorou bastante a incorporar em seu ordenamento jurídico as normas internacionais que repelem a escravidão e o trabalho em condições análogas às de escravo.

O hiato entre as Convenções internacionais e sua incorporação em nosso ordenamento jurídico é bastante significativo na Convenção sobre a Escravatura de Genebra de 1926, que, emendada pelo protocolo de 1953 da Organização das Nações Unidas, foi aprovada no Brasil somente em 1965, pelo Decreto Legislativo ${ }^{13} n^{\circ} 66$ e promulgada pelo Decreto $n^{\circ} 58.563$, de $1^{\circ}$ de junho de 1966. Entre a aprovação, no Brasil, em 1930, da Convenção da Organização Internacional do Trabalho no 29, denominada Convenção sobre Trabalho Forçado, e a sua aprovação, no país, pelo Decreto Legislativo $\mathrm{n}^{\circ} 24$, de 1956, e a sua promulgação pelo Decreto $n^{\circ} 41.721$, de 25 de junho de $1957^{14}$ é grande o lapso temporal.

\footnotetext{
${ }^{10}$ Decreto-lei é ato do chefe do Poder Executivo com força de lei em matéria de competência do Poder Legislativo, importa em uma forma antidemocrática de supremacia do Poder Executivo sobre os demais - previsto na Constituição do Brasil de 1937, nos artigos 13 e 14, mais tarde também previsto na Constituição de 1967, artigo 58, e na Emenda à Constituição de 1967, de nº 01, de 1969, no artigo 55. A figura do decreto-lei não tem previsão na Constituição democrática de 1988. Para consulta às constituições brasileiras anteriores ver: http://www4.planalto.gov.br/legislacao/legislacao-historica/constituicoes-anteriores-1\#content; sobre história constitucional do Brasil, ver: (FACHIN, 2006, p. 81 e seguintes)

${ }^{11}$ Decreto é ato normativo editado pelo chefe do Poder Executivo para regulamentar as leis e dispor sobre a organização da administração pública.

12 Sobre a Carta das Nações Unidas (1945) e os respectivos decretos brasileiros, ver: (MAZZUOLI, 2004, p. 32 e seguintes).

13 Decreto legislativo é procedimento deliberativo especial de competência exclusiva do Congresso Nacional, inclusive quanto a acordos, tratados ou atos internacionais (na Constituição de 1988, previsto no artigo 49, I).

${ }^{14}$ Sobre estas convenções e decretos, ver: (Schwarz, 2008, p.225).
} 
Desde a Convenção sobre a Escravatura de 1926 já se definia a escravidão como o estado ou condição de um indivíduo sobre o qual se exerçam, total ou parcialmente, os poderes característicos do direito de propriedade. Tal definição é a mais simples e a sua constatação é de mais rápida apreensão pelo observador, pois se trata do exercício de posse ostensiva de um ser humano sobre outro, que está sob seu jugo.

Já as condições análogas à da escravidão, algumas delas previstas na Convenção Suplementar sobre a Abolição da Escravatura, do Tráfego de Escravos e das Instituições e Práticas Análogas às da Escravatura (protocolo de 1956), encontram maiores dificuldades para ser reconhecidas pelo observador, seja em razão de cultura, costume, forma de exploração do trabalho, seja simplesmente pela total ausência de simpatia pelos subjugados. São elas: a servidão por dívidas supostamente contraídas pelo trabalhador ou por quem tenha autoridade sobre ele; a servidão por trabalho perenemente imposto em terras de outrem, sem condição de mudança; a entrega de mulher, sem direito de recusa, em casamento; a cessão da mulher pelo seu marido, ou família deste, a terceiro; a transmissão de mulher, por sucessão, em razão da morte do marido, à outra pessoa; e, por fim, qualquer prática através da qual criança (ou adolescente) é dada por seus pais, ou por um deles, ou por quem Ihes faça as vezes, a terceiro para fins de exploração quer da pessoa quer do seu trabalho.

Em todos os casos, a caracterização da condição análoga à de escravo se dá independentemente da forma gratuita ou onerosa pela qual se dá, cede ou transfere a pessoa subjugada.

Tanto na Convenção Suplementar sobre a Abolição da Escravatura, do Tráfego de Escravos e das Instituições e Práticas Análogas à da Escravatura (protocolo de 1956), quanto na Convenção $n^{\circ} 29$ da OIT Sobre o Trabalho Forçado ou Obrigatório, o Brasil, como signatário da Convenção e como membro da Organização Internacional do Trabalho, se obrigou a envidar esforços para a supressão do trabalho escravo, ou em condições análogas em todas as suas formas.

A persistência da exploração do trabalho humano em sua forma mais extrema e violenta (o trabalho escravo) continuava a persistir no Brasil, mesmo nas décadas de 1930-40 e era de conhecimento da sociedade em geral e do legislador. Por ocasião da Exposição de Motivos da Parte Especial do Código Penal (2008) (Decreto-Lei $n^{\circ} 2.848$, de 07 de dezembro de 1940), foi descrita como criminosa a conduta de reduzir alguém, por qualquer meio, à condição análoga à de escravo. Tal condição estaria, dali em diante, tipificada no novo artigo 149. A tipificação da conduta como crime não estava prevista no Código Penal até então vigente. A partir daí ficou declarado sobre tal crime: "É o crime que os antigos chamavam plagium. Não é desconhecida sua prática entre nós, notadamente em certos pontos remotos do nosso hinterland"15 (OLIVEIRA, 1991, p. 29).

Também a Declaração Universal dos Direitos Humanos (1948), 10 de dezembro de 1948 (Resolução 217 A, da Assembleia Geral das Nações

\footnotetext{
${ }^{15}$ Ver: Exposição de Motivos do Código Penal (CÓDIGo PENAL, Decreto-lei $n^{0} 2.848$, de 07/12/1940, organizador OLIVEIRA, Juarez, São Paulo: Saraiva, 1991.
} 
Unidas), em seu artigo IV, repele a utilização de trabalho escravo ou em condições análogas às da escravidão, proibindo a escravidão e o tráfico em todas as suas formas ${ }^{16}$.

Importa destacar que estava em vigência no Brasil, desde 10 de novembro de 1943, a Consolidação das Leis do Trabalho, aprovada pelo Decreto-lei $\mathrm{n}^{\circ}$ 5.452 , de $1^{\circ}$ de maio de 1943. A Consolidação reuniu sistematicamente a legislação trabalhista da época e trouxe novas disposições bastante favoráveis aos empregados, considerados livres na celebração do contrato de trabalho, tendo na liberdade e na irrenunciabilidade aos seus direitos básicos os fundamentos para a validade daquele contrato. A Consolidação, desde sua redação original, em seu artigo 462, já buscava prevenir que o empregado, credor de salários, fosse colocado na posição de devedor do empregador. Após 1967, por força do Decreto-lei 229, o qual acrescentou parágrafos ao artigo 462 da CLT, ficou expressamente vedada a prática do truck system, segundo a qual o empregado é compelido a adquirir do empregador mercadorias ou serviços, muitas vezes em valores abusivos, contraindo dívidas que o colocam em situação de servidão por dívida, uma das formas de condição análoga à de escravo ${ }^{17}$.

A Convenção no 105, de 1957, da Organização Internacional do Trabalho-OIT (órgão da Organização das Nações Unidas), denominada Convenção sobre a Abolição do Trabalho Forçado, foi aprovada no Brasil, somente em 1965, pelo Decreto Legislativo $n^{\circ} 20$ e promulgada pelo Decreto $n^{\circ} 58.822$, de 14 de julho de $1966^{18}$. Referida Convenção também estabelece que todo país-membro da Organização Internacional do Trabalho que a ratifique estará comprometido a adotar medidas para assegurar a imediata e completa abolição do trabalho forçado ou obrigatório.

Ainda na década de 1960 veio à luz o Estatuto da Terra (Lei 4.504/1964) que atribuiu função social à propriedade, especialmente à terra, estabelecendo os princípios da produtividade, da observação da legislação trabalhista, da preservação ambiental e da garantia da saúde daqueles que trabalham na terra.

Entraves ao cumprimento dos direitos fundamentais proviriam da não-aplicação das convenções até então ratificadas pelo Brasil e do não-cumprimento do Estatuto da Terra, na parte da garantia da legislação trabalhista e da liberdade e saúde dos trabalhadores; contudo, o maior entrave, era justamente uma prática do governo ditatorial do Brasil nas décadas de 1960/1970: a política governamental de incentivos fiscais para ocupação da região amazônica. Principalmente a partir da instalação do Projeto Jari, em 1973, milhares de trabalhadores foram arregimentados, especialmente nos estados do Maranhão e Pará, e submetidos a trabalho semisservil ou em condições análogas às de escravo, nas fazendas amazônicas nas quais havia grandes derrubadas de florestas para formação de pastagens. Mais tarde, na década de 1980, as práticas de submissão de trabalhadores a condições análogas às de escravo ainda eram presentes no Brasil, e os poucos trabalhadores libertados pelas autoridades públicas não tinham o pagamento de qualquer indenização, nem

${ }^{16}$ Ver: (NAÇÕES UNIDAS. DECLARAÇÃO Universal dos Direitos Humanos, 1948)

${ }^{17}$ No que tange a CONSOLIDAÇÃO DAS LEIS DO TRABALHO, Ver (COSTA, 2011)

18 Sobre a Convenção no 105 OIT relativa à abolição do trabalho forçado, ver: (Schwarz, 2008) 
havia punição efetiva aos fazendeiros ou aliciadores (SCHWARZ, 2008, p.1403).

O advento da Constituição Federal de 1988 mostra congruência com a matéria até então prevista nos pactos internacionais e na legislação interna, ao declarar, em seu artigo $1^{\circ}$, que a dignidade da pessoa humana e os valores sociais do trabalho são alguns dos princípios fundamentais do Estado brasileiro. A constituição de 1988 , no artigo $4^{\circ}$, II, ainda prevê que o Brasil rege-se em suas relações internacionais pela prevalência dos direitos humanos. A mesma Carta Magna, no artigo $5^{\circ}, \S 2^{\circ}$, proclama que os direitos e garantias nela previstos não excluem outros decorrentes do regime ou dos princípios por ela adotados, ou dos tratados internacionais dos quais o Brasil seja parte. Desse modo, a legislação até aqui referida foi plenamente recepcionada pela Constituição de 1988 e manteve sua vigência dentro da nova ordem constitucional.

Destaque-se, contudo, que, mesmo diante de uma constituição democrática e garantidora da dignidade da pessoa humana e dos direitos fundamentais individuais e sociais, o governo brasileiro continuou a demorar-se a aprovar e promulgar os pactos e tratados internacionais atinentes à proteção do trabalhador e ao repúdio do trabalho escravo ou em condições análogas.

Também foi muito longo o intervalo de tempo entre a celebração do Pacto Internacional de Direitos Econômicos, Sociais e Culturais, adotado pela Resolução n 2220 a (XXI), da Assembleia Geral das Nações Unidas, de 16 de dezembro de 1966, a sua aprovação pelo Brasil, em 1991, através do Decreto Legislativo 226, de 12 de dezembro de 1991, e a sua posterior promulgação, pelo Decreto 591, de 06 de julho de $1992^{19}$. Referido Pacto Internacional sanciona em favor dos indivíduos o direito de ter a possibilidade de ganhar a vida mediante um trabalho livremente escolhido ou aceito, prevendo que cada país que seja parte no pacto tome medidas para salvaguardar o gozo das liberdades políticas e econômicas fundamentais.

Mais de vinte anos se passaram entre a celebração pelos Estados Americanos da Convenção Americana sobre Direitos Humanos (Pacto de San Jose da Costa Rica de 1969) e a adoção pelo Estado brasileiro de legislação e de medidas práticas de combate ao trabalho forçado em todas as suas formas. Nessa Convenção, além da previsão das garantias de liberdade e integridade pessoais e proteção da honra e dignidade, há proibição expressa à escravidão ou à servidão e, mesmo, ao trabalho forçado, imposto por condenação judicial. A Convenção Americana sobre Direitos Humanos (Pacto de San Jose da Costa Rica) foi aprovada no Brasil pelo Decreto Legislativo $\mathrm{n}^{\circ} 27$, de 1992 e promulgada pelo Decreto $n^{\circ} 678$, de 06 de novembro de $1992^{20}$.

$\mathrm{Na}$ década de 1990, as autoridades brasileiras tiveram contra si reclamações apresentadas junto à Organização Internacional do Trabalho-OIT e à Corte Interamericana de Direitos Humanos. Em 1995, a Comissão Interamericana de Direitos Humanos, órgão da Organização dos Estados Americanos, após

\footnotetext{
${ }^{19}$ Sobre Pacto Internacional de Direitos Econômicos, Sociais e Culturais e os respectivos decretos brasileiros, ver: (MAZZUOLI, 2004, p. 488 e seguintes).

${ }^{20}$ Os capítulos e artigos da "Convenção Americana sobre Direitos Humanos" (Pacto de São José da Costa Rica), de 22 de novembro de 1969, estão expostos em: (Schwarz, 2008, p. 231232).
} 
autorização do Estado brasileiro, enviou observadores, os quais, conforme relatório aprovado em 1997, constataram violações graves dos direitos humanos, inclusive a existência de escravidão em todo o país (SCHWARZ, 2008, p.145).

O Protocolo Adicional à Convenção Americana sobre Direitos Humanos em Matéria de Direitos Econômicos, Sociais e Culturais (1988), denominado Protocolo de San Salvador, também consagra o direito ao trabalho - entendido como a oportunidade de obter os meios para levar uma vida digna, com liberdade de escolha da atividade - impondo aos estados-membros o compromisso de garantir plena efetividade do direito ao trabalho. Esse protocolo aguardou, até 1995, pela sua aprovação, a qual foi efetivada no Brasil, por meio do Decreto Legislativo $n^{0} 56$, e veio a ser promulgado pelo Decreto 3.321, somente em 30 de dezembro de $1999^{21}$.

Ressalte-se, ainda, que a partir de 2003 , todos os trabalhadores libertados da condição análoga à de escravos ou de trabalho forçado são imediatamente incluídos no sistema de concessão de seguro-desemprego. Isso porque a lei $\mathrm{n}^{0}$ 10.608, de 20 de dezembro de $2002^{22}$, ao acrescentar o artigo $2^{\circ}-C$ à lei do seguro-desemprego, passou a garantir ao trabalhador o pagamento de saláriodesemprego para aqueles que são assim identificados e resgatados pelas ações do MTE. Na mesma lei, estabelece-se que o trabalhador deve ser encaminhado ao SINE (Sistema Nacional de Emprego), pelo Ministério do Trabalho e Emprego, para qualificação profissional e recolocação no mercado de trabalho.

A Lei 10.803/2003 alterou o artigo 149 do Código Penal brasileiro, para indicar as hipóteses em que determinada situação do trabalhador se configura análoga à de escravo. A nova disposição vem elucidar e detalhar a letra da lei, deixando claro que o trabalho em condições degradantes, o trabalho exaustivo, o trabalho forçado e a servidão por dívida são formas de trabalho em condições análogas à de escravo, e que cada uma dessas formas é, isolada e independentemente, conduta criminosa contra a pessoa. A interpretação da mesma lei, entretanto, tem sido objeto de discordâncias quanto a seu alcance e significado. $\mathrm{Na}$ verdade, o dissenso acerca do que se constitui o trabalho escravo e o trabalho em condições análogas às de escravo, se, por um lado, é característico de um regime democrático, por outro lado mostra a total falta de disposição de alguns setores do Estado e da sociedade em combater esse mal, pois são conceitos que, há muito, vêm sendo esmiuçados nas normas internacionais e nacionais.

Também tem sido enorme a discussão acerca da Proposta de Emenda Constitucional-PEC - 438/2001 $1^{23}$ que dá nova redação ao artigo 243 da Constituição Federal, determinando a pena de perda da gleba, onde for constatada a exploração de trabalho escravo, sem indenização ao proprietário, e revertendo a área ao assentamento dos colonos que já trabalhavam na

${ }^{21}$ Sobre Protocolo de San Salvador (1988) e os respectivos decretos brasileiros, ver: (MAZZUOLI, 2004, p. 552 e seguintes).

${ }^{22}$ Ver a compilação da CONSOLIDAÇÃO DAS LEIS DO TRABALHO, por:: (COSTA, 2011, p. 552).

${ }^{23}$ É importante ter acesso ao seguinte sítio: http://edemocracia.camara.gov.br/web/contra-otrabalho-escravo/andamento-do-projeto/-/blogs/pec-438-2001-contra-o-trabalhoescravo;jsessionid=1CD622A749341B0A7257893AF522E0CC acesso em 12/04/2012 
respectiva gleba. Trata-se de forma de expropriação de terras prevista, até este momento, apenas para culturas ilegais de plantas psicotrópicas. Referida PEC foi apresentada em 1999, originalmente sob o número 57/1999. No Senado Federal, após tramitar durante dois anos, a PEC foi aprovada em 2001. $\mathrm{Na}$ Câmara, em 2004, a matéria foi aprovada em primeiro turno no Plenário da Casa - com 326 votos favoráveis (18 a mais que os 3/5 dos 513 deputados federais exigidos pelo artigo $60, \S 2^{\circ}$, da CF para a aprovação de emendas à constituição). Contudo, desde a sua aprovação em primeiro turno em 2004, ela permanecia à espera da votação em segundo turno.

No dia 22 de maio de 2012 a PEC 438/2001 foi aprovada na Câmara dos Deputados, todavia, o embate político ganhou agora uma nova dimensão, pois ocorreram, na Câmara, alterações no texto da respectiva PEC. Isso a levará ao Senado Federal para uma nova votação. Políticos ligados à frente parlamentar dos Agropecuaristas já estão alardeando que não há uma definição clara do que seja, de fato, trabalho escravo. Uma manobra política que tenta jogar por terra todos os tratados e convenções internacionais, a Carta Constitucional de 1988 e o próprio código penal que define claramente o que é trabalho em condição análoga à de escravo. O deputado federal Homero Pereira, presidente da Frente Parlamentar da Agropecuária, afirma "que o próprio presidente do Tribunal Superior do Trabalho (TST), ministro João Orestes Dalazen, cobrou recentemente mais clareza da legislação que trata do trabalho escravo ou análogo. Segundo ele, os termos 'jornada exaustiva' e 'condições degradantes de trabalho' do artigo 149 do Código Penal são genéricos e dificultam a identificação dos locais onde há trabalho em 'condições análogas às de escravo'. Por razões como essas, a Frente Parlamentar da Agropecuária (FPA), formada por mais de 200 deputados e senadores, decidiu questionar a PEC 438, acolhendo apelos não só do setor produtivo rural como também da indústria e do comércio" (Pereira, 2012, p.3).

O Projeto de Lei 5487/01 do Senado prevê a desapropriação imediata, para fins de reforma agrária, de imóveis rurais onde for localizada cultura ilegal de plantas psicotrópicas, prática de trabalho escravo, ou crime contra o meio ambiente. O projeto, também marcado pela demora da votação e aprovação, acrescenta dispositivos à lei que regulamenta a reforma agrária no Brasil. Pela proposta, as indenizações decorrentes das desapropriações serão pagas somente após o proprietário responsável quitar todas as multas, as perdas e os danos causados a terceiros, os custos sociais, econômicos, ambientais e judiciais, além de outros encargos.

O relator do referido projeto de lei, em 14 de dezembro de 2011, recomendou a rejeição da matéria, pois, segundo ele, a expropriação de terras, onde ocorra cultura ilegal de plantas psicotrópicas, já foi regulamentada. Quanto à desapropriação imediata, em caso de constatação de trabalho escravo ou em condições análogas, o relator, pertencente à Comissão de Agricultura, Pecuária, Abastecimento e Desenvolvimento Rural, alegou que o trabalho escravo não existe na legislação brasileira. Afirmou: "Portanto, o projeto de lei trata de fenômeno jurídico inexistente em nosso ordenamento legal". Ainda 
segundo o mesmo, o crime de "redução à condição análoga à de escravo" já é punido pelo Código Penal ${ }^{24}$.

$\mathrm{Na}$ tramitação desses dois importantes projetos de lei cujos objetivos são, também, o combate ao trabalho escravo ou em condições análogas, fica claro que o processo de avanço não é linear, mas permeado de embates com forças antagônicas, cuja intenção é justamente a manutenção da forma de exploração de mão-de-obra e da impunidade de proprietários rurais e empresários urbanos que desrespeitam inteiramente os direitos dos trabalhadores, inclusive os direitos fundamentais ao trabalho livremente escolhido, com remuneração justa e com respeito à dignidade da pessoa humana.

\section{Da atuação do Executivo - das medidas e instrumentos de combate ao trabalho escravo e em condições análogas}

Nos termos da legislação até aqui trazida para análise, não resta dúvida quanto à existência de farta legislação a prever e rechaçar a prática criminosa da submissão de trabalhadores às condições de escravos ou análogas. Acrescentem-se à legislação todos os compromissos internacionais assumidos pelo Brasil para a proteção e efetivação dos direitos fundamentais, especialmente no que tange ao direito ao trabalho decente, digno e livremente escolhido. Com a legislação interna e a internacional, plenamente recepcionadas pela Constituição Federal de 1988, a qual se funda na dignidade da pessoa humana e na valorização do trabalho humano, a instituição e manutenção de mecanismos de combate ao trabalho escravo ou em condições análogas é dever do Estado brasileiro, cuja missão é garantir a efetivação dos direitos humanos fundamentais.

Em 1995, através de pronunciamento do presidente da República, o Brasil assumiu formalmente a existência do trabalho escravo no país, tornando-se um dos primeiros países a reconhecer oficialmente a ocorrência de formas contemporâneas de escravidão em seu território (SCHWARZ, 2008, p. 144-5).

Ainda em 1995 foi criado o Grupo Especial de Fiscalização Móvel do Ministério do Trabalho, através de Portaria Ministerial $n^{\circ} 550$, de 14 de junho. No mesmo ano foi criado o Grupo Executivo de Repressão ao Trabalho ForçadoGERTRAF, através do Decreto no 1538, de 27 de junho.

As ações fiscais desenvolvidas pelo Grupo Especial de Fiscalização Móvel do Ministério do Trabalho-GEFM têm sido organizadas pela Secretaria de Inspeção do Trabalho - SIT, do Ministério do Trabalho e Emprego, com base em denúncias recebidas sobre a existência de práticas de exploração do trabalho escravo ou em condições análogas nas mais diversas regiões do território brasileiro ${ }^{25}$. Em razão de sua vinculação direta à Secretaria de Inspeção do Trabalho - SIT, situada na capital federal, os grupos móveis atuam de forma mais independente. Pode-se dizer que até um pouco mais

\footnotetext{
${ }^{24}$ Sobre isso é importante consultar o documento: COMISSAO-REJEITA-DESAPROPRIACAODE-TERRAS-COM-TRABALHO-ESCRAVO-OU-PSICOTROPICOS.html. Disponível em: http://www2.camara.gov.br/agencia/noticias/AGROPECUARIA/207178 Acesso em 12/04/2012

${ }^{25}$ Faz-se necessário ver: TRABALHO ESCRAVO NO BRASIL EM RETROSPECTIVA, 2012.
} 
livres das pressões das forças políticas e econômicas presentes em cada região ou estado da federação.

Até o ano de 2002, os grupos móveis compunham-se basicamente de auditores fiscais do trabalho, quando então passou gradativamente a haver participação direta nas diligências por membros da Polícia Federal, do Ministério Público do Trabalho e da Procuradoria Geral da República, além do IBAMA e INCRA (quando necessário e possível), os quais passaram a compor a equipe de fiscalização.

Com clara intenção de continuar a implementar medidas de combate ao trabalho escravo e em condições análogas no Brasil, em 2003, a Presidência da República lançou o Plano Nacional para a Erradicação do Trabalho Escravo e instituiu a Comissão Nacional para a Erradicação do Trabalho Escravo (CONATRAE), a qual substituiu o Grupo Executivo de Repressão ao Trabalho Forçado (GERTRAF).

Nos termos de seu Decreto ${ }^{26}$ criador, a CONATRAE deve acompanhar o cumprimento das ações constantes do Plano Nacional para a Erradicação do Trabalho Escravo e, se entender necessário, propor adaptações e acompanhar a tramitação de projetos de lei relacionados com o combate e erradicação do trabalho escravo no Congresso Nacional. É presidida pelo secretário especial dos Direito Humanos e composta pelos ministros de Estado da Agricultura, Pecuária e Abastecimento, da Defesa, do Desenvolvimento Agrário, do Meio Ambiente, da Previdência Social e do Trabalho e Emprego; também se compõe de dois representantes do Ministério da Justiça, um do Departamento de Polícia Federal e o outro do Departamento de Polícia Rodoviária Federal, e de até nove representantes de entidades privadas não-governamentais, reconhecidas nacionalmente e que possuam atividades relevantes relacionadas ao combate ao trabalho escravo.

Com o fim de conferir efetividade ao Plano Nacional para a Erradicação do Trabalho Escravo, através da Portaria no 1.234, de 17 de novembro de 2003, do Ministério do Trabalho, ficou estabelecido o encaminhamento semestral, para diversos órgãos e entidades da Administração Pública Federal, de relação de empregadores que tivessem sofrido condenação administrativa por descumprimento de dispositivos da legislação trabalhista, ao submeter trabalhadores à condição de trab2alho análoga à de escravo.

Em meio a todo esse movimento de combate ao trabalhado escravo e/ou em condições análogas, ainda em meio ao clamor da comunidade internacional e da sociedade brasileira, que não mais podiam tolerar essa forma extrema e violenta de exploração humana, ocorreu crime bárbaro: a execução de auditores fiscais do Trabalho no efetivo exercício de suas atribuições institucionais no município de Unaí, estado de Minas Gerais. Três auditores fiscais do trabalho e um motorista foram executados em uma emboscada durante uma fiscalização em fazendas daquela região, no dia 28 de janeiro de 2004. Eles investigavam as condições de trabalho escravo em lavouras da região. Os acusados de serem mandantes do crime, detentores de poder político e econômico na região, passados mais de oito anos dos fatos, seguem

$\begin{array}{llllll}26 & \text { Sobre } & \text { o } & \text { respectivo } & \text { Decreto, } & \text { acessar }\end{array}$


sem julgamento, provando que, muitas vezes, as forças do atraso atacam e enfraquecem as práticas que buscam orientar o processo social brasileiro rumo ao desenvolvimento humano e aos direitos humanos.

Mais tarde, o Ministério do Trabalho e Emprego, em 15 de outubro de 2004, editou a Portaria $n^{0} 540$, em substituição à Portaria $n^{0} 1.234$, de 2003; a mais nova estabeleceu o prazo de dois anos para exclusão das empresas transgressoras do Cadastro de Empregadores infratores, desde que eles não reincidissem nas irregularidades, e realizassem o pagamento de multas resultantes da ação fiscal e a quitação de eventuais débitos trabalhistas e previdenciários.

Mais recentemente, veio a Portaria Interministerial $\mathrm{n}^{\circ} 02^{27}$, de 12 de maio de 2011 (DOU de 13/05/2011, Seção I, p. 09), que revogou a Portaria no 540, mas avançou na regulamentação da Lista/Cadastro de Empregadores que tenham submetido trabalhadores a condições análogas às de escravo, completando as previsões das Portarias anteriores e estabelecendo que tal lista será enviada a diversos ministérios e aos bancos que tenham capital público. Prevê, ainda, que a Fiscalização do Trabalho realizará monitoramento pelo período de 2 (dois) anos da data da inclusão do nome do infrator no Cadastro, a fim de verificar a regularidade das condições de trabalho.

Desde 1995 até 2010, nota-se o desenvolvimento da legislação e das normas administrativas em geral e a intensificação dos trabalhos do Grupo Especial de Fiscalização Móvel do Ministério do Trabalho-GEFM, registrando-se um crescente número de fiscalizações e de trabalhadores resgatados da situação de trabalho escravo ou em condições análogas às de escravo. É o que fica demonstrado da análise dos dados do Ministério do Trabalho e EmpregoMTE $^{28}$. No ano de 1995, foram 11 operações fiscais lideradas por auditores fiscais do MTE para erradicação do trabalho escravo e em condições análogas, com 77 estabelecimentos fiscalizados e 906 trabalhadores encontrados em situações análogas às de escravos, conforme as hipóteses previstas no artigo 149 do Código Penal. Estes trabalhadores foram resgatados de ditas condições. O ano de 2008 teve o maior número de operações; foram 158 diligências, 301 estabelecimentos fiscalizados e 4.892 trabalhadores encontrados e resgatados. Em suma, entre 1995 e 2010, um total de 31.589 trabalhadores foram resgatados de condições análogas às de escravos.

\section{Do Judiciário- Das diferentes interpretações dadas à legislação atinente ao trabalho escravo e em condições análogas às da escravidão}

Para Canotilho é característica do Estado de direito ser um Estado constitucional (CANOTILHO, 1999, p.242). A constituição no Estado de direito é

\footnotetext{
27 Para a íntegra da referida Portaria Interministerial $\mathrm{n}^{0}$ 02/2011, ver: http://portal.mte.gov.br/data/files/8A7C816A2E7311D1012FFA7DD87E4E75/p_20110512_2.pdf Acesso em 15/04/2012.

28 Os dados completos sobre as fiscalizações do MTE podem ser encontrados nos Relatórios Específicos de Fiscalização Para Erradicação do Trabalho Escravo. Tabela na íntegra Preparada pelo Ministério do Trabalho e Emprego. Disponível em: http://portal.mte.gov.br/data/files/8A7C816A308E140C013099A935684CEE/quadro_resumo_19 95_2010.pdf. Acesso em 04/04/2012
} 
ordem jurídico-normativa fundamental, dotada de supremacia sobre toda a legislação ordinária e competente para vincular todos os poderes públicos, uma vez que todos os atos praticados devem estar conformes à Constituição.

A Constituição de 1988 inaugurou nova ordem constitucional no Brasil e instituiu um Estado democrático de direito, desde seu preâmbulo, no qual qualifica o Estado brasileiro como "um Estado Democrático, destinado a garantir o exercício dos direitos sociais e individuais, a liberdade, a segurança, o bem-estar, o desenvolvimento, a igualdade e a justiça como valores supremos de uma sociedade fraterna, pluralista e sem preconceitos, fundada na harmonia social [...]" ${ }^{\prime 2}$. Já no artigo $1^{\circ}$, define como um de seus fundamentos a dignidade da pessoa humana. Conclui-se que a Constituição de 1988 funda-se na dignidade da pessoa humana e tem na busca da justiça social o objetivo fundamental do Estado brasileiro.

Da busca de realização da justiça social decorre a proteção dos hipossuficientes, especialmente os trabalhadores, cujos direitos e garantias fundamentais encontram-se no artigo $7^{\circ}$, da Constituição federal.

Os princípios constitucionais e todas as normas internacionais ratificadas pelo Brasil são suficientes e hierarquicamente hábeis para propiciar uma interpretação da legislação nacional condizente com a proteção do trabalhador, especialmente aquele subjugado e mantido em regime de trabalho escravo ou em condição análoga ${ }^{30}$.

O trabalho em condição análoga à de escravo é aquele que está em oposição ao trabalho decente. Trabalho decente é aquele em que há respeito aos direitos mínimos do trabalhador (BRITO FILHO, in GARCIA, 2008, p. 10). Assim, é possível afirmar que trabalho em condição análoga à de escravo é aquele que desrespeita a dignidade da pessoa humana, impedindo total e absolutamente qualquer possibilidade de rumar o país para o desenvolvimento humano.

É possível, também, a conceituação de trabalho escravo ou em condição análoga à de escravo sob o enfoque do direito penal. Para o penalista Nucci (NUCCl, 2008, p.689-690), o significado do artigo 149, caput, do Código Penal, na redação dada pela Lei 10.803/2003, é claro ao enunciar que o trabalho em condições degradantes, o trabalho exaustivo, o trabalho forçado e a servidão por dívida são formas de trabalho em condições análogas à de escravo, e cada uma daquelas condutas descritas é, isolada e independentemente, conduta tipificada como crime, não mais exigindo a nova redação do artigo 149 a união com outros tipos penais, como sequestro e cárcere privado com maus tratos.

A mesma posição tem o penalista Regis Prado (PRADO, 2007, p. 149-50), o qual destaca que a colocação do indivíduo sob o domínio de outrem implica em afronta insanável à dignidade da pessoa humana. Para tanto não se exige que a vítima esteja enclausurada, sofra maus-tratos ou haja trabalho sem remuneração, bastando a ocorrência de condições degradantes, ou jornada esgotante, ou trabalhos forçados ou limitação na liberdade de abandonar o

\footnotetext{
${ }^{29}$ BRASIL. Constituição (1988). Preâmbulo da Constituição da República Federativa do Brasil. Brasília, DF 1988 in VADEMECUM, Saraiva, 2010, p. 7.

${ }^{30}$ Sobre o combate ao trabalho escravo no Brasil, ver: (Lotto, 2008; Trabalho Escravo no Brasil em retrospectiva, 2012).
} 
emprego em razão de dívida contraída junto ao empregador ou seu preposto. Por fim, esclarece que o consentimento da vítima é irrelevante, por importar anulação da personalidade, o que é impossível do ponto de vista jurídico, já que todos os seres humanos são dotados de personalidade e são titulares de direitos fundamentais irrenunciáveis.

As decisões judiciais na Justiça do Trabalho vêm construindo sua interpretação do que caracterizaria a redução à condição análoga à de escravo, rejeitando a chamada terceirização da atividade-fim economicamente explorada pelo empregador (o que afasta o aliciamento por pessoas interpostas) e admitindo como indícios de prestação de serviços em condições análogas às de escravo a falta de instalações adequadas para dormir ou trabalhar, o atraso persistente no pagamento de salários, a jornada exaustiva, com supressão da folga semanal e a retenção do trabalhador, pelo empregador, e falta de registro em Carteira de Trabalho e Previdência Social-CTPS. (TRT-PR-00705-2009-74909-00-8-ACO-00146-2012 - 2A. TURMA. Relator: ANA CAROLINA ZAINA. Publicado no DEJT em 18-01-2012) ${ }^{31}$. Também podem ser encontradas decisões nas quais o julgador demonstre preocupação com qualquer espécie de desvirtuamento do contrato que possibilite o não- pagamento de salários pelo empregador, enunciando que "não há como convalidar a atitude patronal consistente no beneficiamento de labor humano sem a devida contraprestação pecuniária, sob pena de se albergar o trabalho escravo" (TRT-PR-01479-2004014-09-00-7-ACO-02402-2007 - 4A. TURMA. Relator: LUIZ CELSO NAPP. Publicado no DJPR em 02-02-2007) ${ }^{32}$.

É necessário destacar, contudo, que a justiça trabalhista não tem decidido, de forma uniforme, o que seja degradância ou trabalho forçado, para a caracterização de condição análoga à de escravo, e isso dificulta o enquadramento dos trabalhadores encontrados pelos grupos móveis de fiscalização do Ministério do Trabalho como vítimas do crime de redução à condição análoga à de escravo, para o recebimento de indenização. Há casos em que as decisões judiciais parecem entender que a degradância não é suficiente; seria necessária a coexistência do cerceamento da liberdade (TRT $23^{\mathrm{a}}$ R.-RO- 00335.2007.071.23.00-4-2a T.- Rel. Des. Osmair Couto - DJMT 26.10.2007 in GARCIA, 2008, p. 32).

Muitos dos empregadores criminosos que se utilizam de trabalho escravo ou em condições análogas em seus empreendimentos, rurais ou urbanos, inconformados com as punições recebidas, caracterizadas, basicamente pelas multas decorrentes dos autos de infração lavrados pelos auditores fiscais do Ministério do Trabalho e Emprego, pelas indenizações a serem pagas aos trabalhadores e pela inclusão no Cadastro do MTE, também conhecido como "Lista Suja", levam ao Poder Judiciário suas solicitações para se verem livres das sanções impostas. No que tange à manutenção de empregadores no

\footnotetext{
${ }^{31}$ Vejam-se as seguintes jurisprudências: TRT-PR-00705-2009-749-09-00-8-ACO-00146-2012 2A. TURMA. Publicado no DEJT em 18-01-2012. Disponível em: http://www.trt9.jus.br/internet_base/jurisprudenciaman.do?evento=Editar\&chPlc=4666653 Acessado em: 21/04/2012

${ }^{32}$ Vejam-se as seguintes jurisprudências: TRT-PR-01479-2004-014-09-00-7-ACO-02402-2007 4A. TURMA. Publicado no DJPR em 02-02-2007. Disponível em: http://www.trt9.jus.br/internet_base/jurisprudenciaman.do?evento=Editar\&chPlc=2378009 Acessado em: 21/04/2012.
} 
Cadastro do MTE, apesar da ausência de uniformidade, as decisões judiciais da justiça laboral têm sido de grande valia (TRT 10a R.-RO00856.2006.006.10.00-2-2a T.- Rel. Juiz João Amílcar - DJU 3 16.11.2007 in GARCIA, 2008, p. 32).

Contudo, nesse caminhar, nem sempre os responsáveis pelas práticas criminosas aqui tratadas sofrem as punições necessárias e devidas; isso porque há casos em que decisões judiciais fundamentam-se expressamente em interpretações restritivas dos conceitos de dignidade da pessoa humana, trabalho decente e trabalho degradante. Schwarz (2008, p.118) aponta a existência de um alto grau de impunidade na esfera penal. Pela consistência de sua verificação, vale a transcrição:

"De fato, embora a supressão do status libertatis no crime de plagium não seja realmente de difícil constatação, e a sua prática não seja desconhecida entre nós, notadamente em certos pontos mais afastados de nosso hinterland, o certo é que a concreta possibilidade de agravamento das sanções penais, multas e restrições administrativas, e, mais, de eventual expropriação de terras, torna necessária uma precisa definição do que caracteriza o trabalho escravo na contemporaneidade. (...) na nota de rodapé: Destacamos, nesse contexto, que até hoje não há, no Brasil, uma única pessoa privada da liberdade em decorrência de condenação criminal definitiva, relacionada ao crime previsto no art. 149 o Código Penal. Além disso, segundo Castilho (1994, p. 24), o suposto "consentimento" da vítima "nas hipóteses denunciadas como de trabalho escravo tem funcionado como causa supralegal de exclusão da antijuridicidade penal, até porque [em muitos casos] sequer se instaura o inquérito policial". (Schwarz, 2008, p.118)

\section{Considerações finais}

O RDH de 2000 preocupa-se em demonstrar que o desenvolvimento humano e os direitos humanos possuem uma base comum, a qual se assenta, inteiramente, em três pilares: liberdade, bem-estar e dignidade. $\mathrm{O}$ trabalho em condição análoga à de escravo implode todos eles. Por isso, o empenho no combate a esse tipo de trabalho condensa investimentos que tentam direcionar o país no sentido tanto de melhorias no IDH quanto de avanços no campo da efetivação dos direitos. Todas as morosidades, resistências, impedimentos e formas de obstar à eliminação das formas de trabalho similar à da escravidão subtraem não só a expansão dos direitos humanos, mas também do desenvolvimento humano.

A análise dos procedimentos dos Poderes Executivo, Legislativo e Judiciário possibilita constatar que, apesar dos avanços, ainda persistem inúmeras dificuldades para a erradicação do trabalho em condição análoga à de escravo. Há problemas de ordem procedimental, de ordem política, de ordem econômica, de ordem social e de ordem cultural. Os de natureza política podem ser facilmente constatados quando se analisam os Projetos-Leis ${ }^{33}$ que

\footnotetext{
${ }^{33}$ Isto foi desenvolvido pelos pesquisadores: (Romero e Sprandel, 2003)
} 
têm tramitado no Congresso, no decorrer das décadas de 1990 e 2000, para definir punições daqueles que lançam mão do trabalho escravo em suas propriedades. A vagareza, o desinteresse, as resistências e as conivências mostram que se perpetuam, no âmbito institucional, lógicas de interesses sustentadores de práticas escravagistas. Os problemas de natureza socioeconômica expressam-se na profundidade do abismo entre os mais abastados e os mais empobrecidos.

O fato de haver, na sociedade brasileira, indivíduos que estão na situação de miséria absoluta, favorece, enormemente, não só a indução das pessoas pobres a aceitar serviços que subtraem toda e qualquer dignidade e liberdade dos trabalhadores, mas também a reincidência destes levados pelo desespero de uma vida extremamente precária que os conduzem às condições análogas à de escravo. Muitas vezes, os escravizados que foram resgatados retornam, novamente iludidos por agenciadores, à situação de exploração e de impotência.

"A erradicação da pobreza constitui uma tarefa importantes dos direitos humanos no século XXI. Um nível decente de vida, nutrição suficiente, atenção a saúde, educação, trabalho decente e proteção contra as calamidades não são simplesmente metas do desenvolvimento, são também direitos humanos" (RDH, 2000, p.8).

E por que se considera que as dificuldades de erradicação do trabalho escravo, no país, contêm também problemas de natureza cultural? Prevalece, no Brasil, uma mentalidade recorrente de indiferença diante da subtração de direitos das pessoas mais pobres. Considera-se, no entanto, que nas últimas duas décadas as ações do Executivo, ao lançar os planos nacionais de direitos humanos e de erradicação do trabalho escravo, têm sido um investimento que tende a fazer que se torne pública a necessidade de desenvolver uma consciência, na sociedade como um todo, rechaçadora dessa prática criminosa que tem colocado o país entre aqueles que não conseguem superar a mácula da condenação de inúmeros indivíduos a algumas formas de sofrimento social extremo.

Os desafios estão postos, então, para todos os poderes, todas as instâncias, todas as organizações da sociedade, todas as instituições. Quanto mais se tornarem públicas as condições atuais de escravização de inúmeros brasileiros, os investimentos, os embates, as resistências, os avanços e não-avanços no combate a tais situações de escravização, mais a sociedade pode obter conhecimentos sobre tais fatos. É esse um primeiro passo, já que "sem o conhecimento da verdade não se muda nada" (CANDIDO, 1999, p.6). 


\section{Bibliografia e outras fontes}

(1988) ALMEIDA, Alfredo. W. B. de. Cativeiro hoje: O trabalho como instrumento de escravidão. Humanidades, Brasília, V.5, n.17, p.19, dezembro.

(1990) ALMEIDA, Alfredo. W. B. de. Terra, conflito e cidadania. Paris: Lelio Bassos Foundation.

(2010) AYRES BRITO apud Vannuchi, P. País não pode tolerar trabalho escravo. Folha de S. Paulo, São Paulo, 17 jun. C.A, p.3

(2008) BARRETO, Cláudia. M. S. P. Trabalho escravo urbano responsabilidade do empregador e as condições do trabalhador estrangeiro em situação de permanência irregular no Brasil. Revista IOB Trabalhista e Previdenciária, São Paulo, vol. 21, nº 241, p. 80-105.

(1992) BARROZO, João. C. Exploração e escravidão nas agropecuárias da Amazônia mato-grossense. São Paulo, Dissertação de mestrado, Universidade de Campinas.

(2004) BRITO FILHO, José. C. M. Trabalho Decente - análise jurídica da exploração, trabalho forçado e outras formas de trabalho indigno, São Paulo: LTr.

(1996) CANDIDO, Antônio. Para pensar o problema da fome. Folha de S. Paulo, São Paulo, 29 nov. C6, p.6.

(1999) CANOTILHO, José. J. G. Direito constitucional e teoria da constituição. Coimbra: Portugal: editora Livraria Almedina.

(1994) CASTILHO, Ela. W. de. Trabalho forçado e trabalho escravo no direito penal brasileiro. Florianópolis: UFSC.

(1988) BRASIL. Constituição. Preâmbulo da Constituição da República Federativa do Brasil. Brasília: DF.

(2010) BRASIL. DETRAE. Divisão de Fiscalização para Erradicação do Trabalho Escravo. Quadro geral das operações de fiscalização para erradicação do trabalho escravo - SIT/SRTE - 1995-2010. Disponível em: http://www.mte.gov.br/fisca_trab/quadro_resumo_1995-2010/pdf Acessado em 01/05/2010.

(2003) BRASIL. PLANO NACIONAL PARA ERRADICAÇÃO DO TRABALHO ESCRAVO. Ministério do Trabalho e Emprego. Disponível em: http://www.mte.gov.br/geral/funcoes/imprimir.asp?URL+/trab_escravo/erradicaç ão_trab_escravo.asp Acessado em: 27/04/2010.

(2010) BRASIL. MTE. Relatórios Específicos de Fiscalização Para Erradicação do Trabalho Escravo. 1995-2010. Tabela na íntegra Preparada pelo MTE. Disponível

em: 
http://portal.mte.gov.br/data/files/8A7C816A308E140C013099A935684CEE/qu adro_resumo_1995_2010.pdf. Acesso em 04/04/2012

(2011) COSTA, Armado. C.; FERRARI, Irany. e MARTINS, Melchíades. R. [compilação de]. CONSOLIDAÇÃO DAS LEIS DO TRABALHO. São Paulo: LTr.

(2008) CÓDIGO Penal Comentado. Revista dos Tribunais.

(2003) DRAIBE, Sônia. M. A política social no período FHC e o sistema de proteção social. Tempo Social, São Paulo, v.15, n.2, p.63-97, dezembro.

(1994) ELIAS, Norbert. O processo civilizador: Formação do Estado e civilização. Rio de Janeiro: Jorge Zahar, V.2.

(2006) ELIAS, Norbert. Conceitos sociológicos fundamentais: civilização, figuração, processos sociais. In NEIBURG, F. e WAIZBORT, L. (orgs.) Escritos \& Ensaios. Rio de Janeiro: Jorge Zahar, p.21-33.

(2006a) ELIAS, Norbert. Tecnização e civilização. In NEIBURG, F. e WAIZBORT, L. (orgs.) Escritos \& Ensaios. Rio de Janeiro: Jorge Zahar, p.3567.

(2006b) ELIAS, Norbert. Processos de formação de Estados e construção de nações. In NEIBURG, F. e WAIZBORT, L. (orgs.) Escritos \& Ensaios. Rio de Janeiro: Jorge Zahar, p.153-165.

(1987) ESTÉRCI, Neide. Conflito no Araguaia; peões, posseiros contra a grande empresa. Petrópolis: Vozes.

(2006) FACHIN, Zulmar. Teoria geral do direito constitucional. Londrina: Eduel.

(2008) GARCIA, Gustavo. F. B. Trabalho análogo à condição de escravo e degradante: antítese do trabalho decente. Revista IOB Trabalhista e Previdenciária, São Paulo, vol. 19, nº 224, p.07-34.

(2008) KAPLAN, Carina. (org.). La civilización en cuestión: escritos inspirados en la obra de Norbert Elias. Buenos Aires: Nino y Dávila.

(2009) KAPLAN, Carina. y ORCE, Victória. (Coords). Poder, prácticas sociales y proceso civilizador: Ios usos de Norbert Elias. Buenos Aires: Noveduc.

(1993) LIMA, Ireno. J. S. Cantinas garimpeiras: um estudo das relações sociais nos garimpos de ouro no Tapajós. Belém: Secretaria Indústria, Comércio e Mineração do Estado do Pará.

(2008) LOTTO, Luciana A. Ação civil pública trabalhista contra o trabalho escravo no Brasil. São Paulo: LTr.

(1994) MARTINS. José. de S. A militarização da questão agrária no Brasil. Petrópolis: Vozes.

(1986) MARTINS, José. de S. Escravidão hoje no Brasil. Folha de S. Paulo, São Paulo, 13 maio. C1, p.3.

(1995) MARTINS, José. de S. A reprodução do capital na frente pioneira e o renascimento da escravidão no Brasil. Tempo Social, São Paulo, v.6, n.1-2, p. 1-25, dezembro.

(2004) MAZZUOLI, Valério. de O. (organizador). Coletânea de Direito Internacional. São Paulo: Revista dos Tribunais. 
(1948) NAÇÕES UNIDAS. DECLARAÇÃO UNIVERSAL DOS DIRIETOS HUMANOS, 10 de dezembro de 1948. Disponível em: http://unesdoc.unesco.org/images/0013/001394/139423por.pdf. Acessado em 01/10/2010

(1990) NAÇÕES UNIDAS. PNUD, RDH. Definição e medição do desenvolvimento humano - Relatório do Desenvolvimento Humano 1990. Disponível em: http://hdr.undp.org/en/reports/global/hdr1990 [Acessado em 02/03/2011]

(1993) NAÇÕES UNIDAS. PNUD, RDH. Participação popular - Relatório do Desenvolvimento Humano. Disponível em: Disponível em: http://hdr.undp.org/en/reports/global/hdr1993 [Acessado em 02/03/2011]

(1996) NAÇÕES UNIDAS. PNUD, RDH. Tendências do crescimento econômico e do desenvolvimento humano - Relatório do Desenvolvimento Humano. Disponível em: Disponível em: http://hdr.undp.org/en/media/hdr-1996 [Acessado em 12/05/2011]

(2000) NAÇÕES UNIDAS. PNUD, RDH. Direitos Humanos e desenvolvimento humano: em prol da liberdade e da solidariedade. Relatório do Desenvolvimento Humano. Disponível em: http://www.pnud.org.br/rdh [Acessado em: 11/05/2012].

(2002) NAÇÕES UNIDAS. PNUD, RDH. Relatório do Desenvolvimento Humano: Aprofundar a democracia em um mundo fragmentado. Disponível em: http://hdr.undp.org/en/reports/global/hdr2002 Acessado em 28/03/2011.

(2003) NAÇÕES UNIDAS. PNUD, RDH. Um pacto entre as nações para eliminar a pobreza humana - Relatório do Desenvolvimento Humano. Disponível em: Disponível em: http://hdr.undp.org/en/reports/global/hdr2003 [Acessado em 02/03/2011]

(2006) NAÇÕES UNIDAS. PNUD, RDH. Além da escassez: poder, pobreza e as crises mundiais da água. Relatório do Desenvolvimento Humano. Disponível em: Disponível em: http://hdr.undp.org/en/reports/global/hdr2006 [Acessado em 12/03/2011]

(2008) NUCCl, Guilherme. de S. Código penal comentado. São Paulo: Revista dos Tribunais.

(1991) OLIVEIRA, Juarez (org.). Código penal. São Paulo: Saraiva.

(2008) PALO NETO, Vito. Conceito jurídico e combate ao trabalho escravo contemporâneo. São Paulo: LTr.

(2008) PEREIRA, Gadyson. S. B. A escravidão contemporânea no Brasil: a trajetória história de um debate teórico-metodológico e político (1985-2003) AEDOS, v.1, n.1, p. 1-8. Disponível em: http://www.seer.ufrgs.br/index.php/aedos/article/view/9820/5622 Acesso em 27/04/2010.

(2012) PEREIRA, Homero. 2012. O guarda da esquina. Folha de S. Paulo, São Paulo, 04 jun. C1, p.3.

(2007) PRADO, Luiz. R. Comentários ao Código Penal. São Paulo: Revista dos Tribunais. 
(2003) RELATÓRIO. Rede Social de justiça e direitos humanos. São Paulo, Rede Social de Justiça e Direitos Humanos, p.1-9. Disponível em: http://www.social.org.br/relatorio2003/relatorio014.htm Acesso em 28/04/2010.

(1992) REZENDE FIGUEIRA, Ricardo. R. Rio Maria: canto da terra. Petrópolis, Vozes.

(1999) REZENDE FIGUEIRA, Ricardo. Condenados à escravidão apud Trabalho escravo no Brasil contemporâneo. Goiânia, São Paulo, CPT/Loyola, p.165-208.

(2004) REZENDE FIGUEIRA, Ricardo. Pisando fora da própria sombra: a escravidão por dívida contemporânea. Rio de Janeiro, Civilização Brasileira.

(2009) REZENDE FIGUEIRA, Ricardo.. A escravidão contemporânea no Brasil: de 1985 a 2009 in Direitos humanos no Brasil 2009: relatório da Rede Social de justiça e direitos humanos. São Paulo, Rede Social de Justiça e Direitos Humanos, p.1-9. Disponível em: http://www.gptec.cfch.ufrj.br/artigos/rede_social_2009.pdf Acesso em 28/04/2010.

(2003) ROMERO, Adriana. M. e SPRANDEL, Márcia. A. Trabalho escravo algumas reflexões. CEJ, Brasília, n.22, p.119-132, jul.set

(2008) SANTOS, Ronaldo. L. dos. A escravidão por dívidas nas relações de trabalho no Brasil contemporâneo, Revista do Ministério Público do Trabalho in LOTTO, Luciana A. Ação civil pública trabalhista contra o trabalho escravo no Brasil. São Paulo: LTr, p..33.

(2008) SCHWARZ, Rodrigo. G. Trabalho escravo - a abolição necessária. São Paulo: Ltr.

(2007) SILVA, Alessandro; MAIOR, Jorge. L S.; FELIPPE, Kenarik. B. e SEMER, Marcelo. (coords.). Direitos Humanos: essência do direito do trabalho. São Paulo: LTr.

(2004) SILVA, José. A. Curso de direito constitucional positivo. São Paulo: Malheiros editores..

(1999) SILVA, Maria. A. de M. Errantes do fim do século. São Paulo, Unesp.

(1994) SUTTON, Alisson. Trabalho escravo: um elo na cadeia da modernização no Brasil hoje. São Paulo, Loyola.

(2012) TRABALHO ESCRAVO NO BRASIL EM RETROSPECTIVA: Referências para estudos e pesquisas. Disponível em: http://portal.mte.gov.br/data/files/8A7C816A350AC882013543FDF74540AB/retr ospec_trab_escravo.pdf . Acesso em 12/04/2012

(2011) TRABALHO degradante cresce em obras. Folha de S. Paulo, São Paulo, 20 mar. CA, p.12.

(2010) VADE MECUM. Obra coletiva de autoria de Editora Saraiva, com colaboração de Antônio Luiz de Toledo Pinto, Márcia Cristina Vaz dos Santos Windt e Lívia Céspedes. São Paulo: Saraiva. 


\section{Jurisprudências}

(2012) TIBUNAL REGIONAL do TRABALHO-PR-00705-2009-749-09-00-8ACO-00146-2012 - 2A. TURMA. Publicado no DEJT em 18-01-2012. Disponível em: http://www.trt9.jus.br/internet_base/jurisprudenciaman.do?evento=Editar\&chPlc $=4666653$ Acessado em: 21/04/2012

(2007) TRIBUNAL REGIONAL do TRABALHO-PR-01479-2004-014-09-00-7ACO-02402-2007 - 4A. TURMA. Publicado no DJPR em 02-02-2007. Disponível em: http://www.trt9.jus.br/internet_base/jurisprudenciaman.do?evento=Editar\&chPIc $=2378009$ Acessado em: 21/04/2012. 